\title{
Basınç Yaralanmalı Hastaların Tedavisinde Beslenmenin Etkisi
}

\author{
Maide YEŞILILURT ${ }^{1}$ (D) Serpil YÜKSEL ${ }^{2}$ iD \\ ${ }^{1}$ Necmettin Erbakan Üniversitesi, Hemşirelik Fakültesi, Hemşirelik Bölümü, Konya, Türkiye, md91yesilyurt@gmail.com \\ (Corresponding Author / Sorumlu Yazar) \\ ${ }^{2}$ Necmettin Erbakan Üniversitesi, Hemşirelik Fakültesi, Hemşirelik Bölümü, Konya, Türkiye, yukselserpil1977@ gmail.com
}

\begin{tabular}{|c|c|}
\hline Makale Bilgileri & ÖZ \\
\hline $\begin{array}{l}\text { Makale Geçmişi } \\
\text { Geliş: } 13.09 .2020 \\
\text { Kabul: } 03.11 .2020 \\
\text { Yayın: 25.12.2020 } \\
\text { Anahtar Kelimeler: } \\
\text { Basınç yaralanmaları, } \\
\text { Beslenme, } \\
\text { Hasta, } \\
\text { Tedavi. }\end{array}$ & $\begin{array}{l}\text { Basınç yaralanmaları, fiziksel ve psikolojik travmaya neden olan, yaşam kalitesini azaltan, } \\
\text { hastanede kalış süresini uzatarak tedavi ve bakım maliyetini artıran ciddi kronik yaralardır. Basınç } \\
\text { yaralanmalarının görülme sıklığı her klinik ortamda farklılık göstermekte olup, akut bakım } \\
\text { ortamlarında görülme oranının \%10-29 aralığında değiştiği bildirilmiştir. Büyük oranda önlenebilir } \\
\text { bir komplikasyon olan bu yaralanmaların oluşumunda etkili başlıca risk faktörleri; basınç, yırtılma, } \\
\text { sürtünme, hareketsizlik, ileri yaş, duyusal kayıplar ve beslenme bozukluklarıdır. Yeterli ve dengeli } \\
\text { beslenme, hem basınç yaralanmalarının önlenmesinde hem de tedavi ve bakımında önemlidir. } \\
\text { Ulusal Basınç Yaralanması Danışma Paneli'nin } 2019 \text { yılı rehberinde, yeterli beslenemeyen Evre II } \\
\text { basınç yaralanmalı hastalara yüksek kalorili ve proteinli, arginin, çinko ve oral antioksidan içeren } \\
\text { oral besin takviyeleri verilmesi önerilmektedir (Kanıt Düzeyi=B). Literatür incelendiğinde, protein, } \\
\text { karbonhidratlar, vitaminler ve mineraller gibi temel besin maddelerinin yeterli alımının, basınç } \\
\text { yaralanmalarının tedavisinde önemli olduğu görülmüştür. Yeterli beslenemeyen hastalara normal } \\
\text { beslenmenin yanı sıra yüksek kalorili ve protein takviyeleri verilmesi önerilmektedir. Ayrıca } \\
\text { araştırmalar, A, C, E vitaminleri, çinko, bakır (Cu), demir (Fe) ve folik asit takviyeleri ile } \\
\text { zenginleştirilmiş yüksek proteinli besin takviyelerinin oral alımının, basınç yaralanmalarının } \\
\text { iyileşmesini hızlandırabileceğini göstermiştir. Bu derleme, mevcut literatüre dayanarak, besin } \\
\text { takviyelerinin basınç yaralanmalarının tedavisinde etkisini ve yara iyileşmesinde etkili rolünü } \\
\text { tartışmayı amaçlamaktadır. Hemşirelere, kanıta dayalı çalışmaların kılavuzluğunda hastalara özel } \\
\text { beslenme protokolleri oluşturmaları ve uygulamaları önerilmektedir. }\end{array}$ \\
\hline
\end{tabular}

\section{The Effect Of Nutrition In The Treatment Of Pressure Injury Patients}

\begin{tabular}{ll}
\hline Article Info & ABSTRACT \\
\hline $\begin{array}{l}\text { Article History } \\
\text { Received: } 13.09 .2020 \\
\text { Accepted: } 03.11 .2020 \\
\text { Published: } 25.12 .2020\end{array}$ & $\begin{array}{l}\text { Pressure injuries are an important health problem that causes trauma physically and } \\
\text { psychologically, decreases the quality of life, increase the cost of treatment and prolongs hospital } \\
\text { stay. The incidence of pressure injuries varies in every clinical setting, and it has been reported that } \\
\text { the incidence in acute care settings varies between 10-29\%. The main risk factors for these injuries, } \\
\text { which are largely preventable complications; pressure, tearing, friction, immobility, advanced age, } \\
\text { sensory losses and nutritional disorders. Adequate and balanced nutrition is important both in the } \\
\text { Keywords: }\end{array}$ \\
$\begin{array}{l}\text { prevention and treatment and care of pressure injuries. In the 2019 guide of the National Pressure } \\
\text { Inutrition, }\end{array}$ & $\begin{array}{l}\text { Injury Advisory Panel, it is recommended that patients with Stage II pressure injuries who cannot } \\
\text { be fed adequately should be given oral nutritional supplements with high calorie and protein, } \\
\text { containing arginine, zinc and oral antioxidants (Level of Evidence = B). A review of the literature } \\
\text { showed } \\
\text { sheatment. } \\
\text { minerals is important in the treatment of pressure injuries. It is recommended to give high-calorie } \\
\text { and protein supplements in addition to the normal diet to patients who cannot consume adequate } \\
\text { nutrition. Besides, studies have shown that consuming high protein oral nutritional supplements } \\
\text { enriched with vitamins A, C, E, and zinc and copper (Cu), iron (Fe), and folic acid supplements } \\
\text { can accelerate the healing of pressure injuries. This review aimed to discuss the effect of nutritional } \\
\text { supplements in the treatment of pressure injuries and their influencing role in wound healing based } \\
\text { on current literature. Nurses are recommended to create and implement patient-specific nutrition } \\
\text { protocols under the guidance of evidence-based studies. }\end{array}$
\end{tabular}

Atıf/Citation: Yeşilyurt, M. \& Yüksel, S. (2020). Basınç yaralanmalı hastaların tedavisinde beslenmenin etkisi, Genel Sağllk Bilimleri Dergisi, 2(3), 200-207. 


\section{GİRIŞ}

Büyük oranda önlenebilir bir komplikasyon olan basıç yaralanmaları, morbidite ve mortalite oranlarının artmasına, infeksiyon, ağrı ve depresyon gibi sorunlara, bireyin hastanede kalış süresinin uzamasına, ek tedavi ve bakım maliyetine neden olan ciddi kronik yaralardır (NPUAP, EPUAP ve PPPIA, 2014; Chaboyer ve diğerleri 2015). Hastanede tedavi ve bakım uygulanan hastaların \%10-30'unda basınç yaralanmalarının oluştuğu (Chaboyer ve diğerleri 2015), özellikle hareketsizlik, duyusal yetersizlik, hipoalbüminemi, inkontinans, yetersiz doku perfüzyonu ve beslenme bozukluğu gibi sorunların riski artırdığg belirlenmiştir (Coyer ve diğerleri 2015; Coyer ve diğerleri 2016). Yetersiz ve dengesiz beslenmenin basınç yaralanması riskini artırdığını ve yara iyileşmesini geciktirdiğini ortaya koyan çalışmalar (Landau, 2014; Posthauer, Banks, Dorner ve Schols, 2015; Cereda, Neyens, Caccialanza, Rondanelli ve Schols, 2017) ve rehberler (EPUAP ve NPUAP, 2009; NPUAP, EPUAP ve PPPIA 2014,2019), basınç yaralanmalarının önlenmesinde ve tedavisinde beslenmenin önemine dikkati çekmiştir. $\mathrm{Bu}$ derlemede, basınç yaralanmalarının tedavisinde etkili besin takviyelerini ve bunların yara iyileşmesindeki önemini, hemşirenin rolünü mevcut literatür doğrultusunda tartışmak amaçlandı.

\section{Basınç Yaralanmaları}

Ulusal Basınç Yaralanması Danışma Paneli (National Pressure Injury Advisory Panel-NPIAP), Avrupa Basınç Yaralanması Danışma Paneli (European Pressure Ulcer Advisory Panel-EPUAP) ve Pan Pasifik Basınç Yaralanması Birliği'nin (Pan Pacific Pressure Ulcer Alliance- PPIA) rehberlerinde basınç yaralanmaları, genellikle bir kemik çıkıntı üzerinde veya bir tıbbi araç ya da başka bir araçla ilişkili olarak deride veya derin dokularda oluşan lokalize hasar olarak tanımlanmaktadır (EPUAP ve NPUAP 2009; NPUAP, EPUAP ve PPPIA 2014). Aynı rehberlerde basınç yaralanmaları, etkilenen doku tabakaları dikkate alınarak altı evre olarak sınıflandırılmış (Tablo 1), evrelere göre uygulanması gereken tedavi ve bakım girişimleri tanımlanmıştır (EPUAP ve NPUAP 2009; NPUAP, EPUAP ve PPPIA 2014).

Tablo 1. Basınç Yaralanmalarının Evreleri ve Özellikleri

\begin{tabular}{|c|c|c|}
\hline Sinıflandırma & Tanım & Özellikleri \\
\hline I. Evre & $\begin{array}{l}\text { Deride basmakla } \\
\text { solmayan kizariklik }\end{array}$ & $\begin{array}{l}\text { Deri bütünlüğü bozulmamıştır, parmakla basmakla solmayan } \\
\text { kızarıklık vardır. }\end{array}$ \\
\hline II. Evre & $\begin{array}{l}\text { Dermis tabakasının } \\
\text { kısmi kaybı ve vezikül }\end{array}$ & $\begin{array}{l}\text { Bu evre yüzeysel açık yaralanma şeklinde görünen, sarı nekrotik doku } \\
\text { bulunmayan kırmızımsı pembe renkte yara yatağına sahip kısmi } \\
\text { kalınlıkta dermis kaybıdır. }\end{array}$ \\
\hline III. Evre & $\begin{array}{l}\text { Deri ve subkütan doku } \\
\text { tabakalarında kayıp }\end{array}$ & $\begin{array}{l}\text { Bu evrede tam kalınlıkta doku kaybı vardır. Yara yatağında deri altı } \\
\text { yağ dokusu görülebilir, fakat kemik, tendon ya da kaslar } \\
\text { etkilenmemiştir. Yarada cepler ve tüneller bulunabilir. }\end{array}$ \\
\hline IV. Evre & $\begin{array}{l}\text { Tam kalınlıkta doku } \\
\text { kaybı }\end{array}$ & $\begin{array}{l}\text { Bu evrede, kemik, tendon veya kasların etkilendiği tam kalınlıkta } \\
\text { doku kaybı vardır. Sarı nekrotik doku veya eskar bulunabilir. Sıklıkla } \\
\text { cepleşme ve tünelleşme vardır. }\end{array}$ \\
\hline $\begin{array}{l}\text { Şüpheli derin doku } \\
\text { hasarı }\end{array}$ & $\begin{array}{l}\text { mor ya da } \\
\text { rengi değişiklik }\end{array}$ & $\begin{array}{l}\text { Deri bütünlüğü bozulmamış ancak ciltte mor ya da kestane renginde } \\
\text { değişiklik ya da içi kan dolu büller vardır. }\end{array}$ \\
\hline $\begin{array}{l}\text { Evrelendirilemeyen } \\
\text { evre }\end{array}$ & $\begin{array}{l}\text { Eskar dokusu ile kaplı } \\
\text { yara }\end{array}$ & $\begin{array}{l}\text { Tam kalınlıkta doku kaybı vardır ancak yara yatağı eskar dokusu ile } \\
\text { kaplıdır. Nekrotik dokular uzaklaştırılıncaya kadar yaranın gerçek } \\
\text { evresi belirlenemez }\end{array}$ \\
\hline
\end{tabular}

Basınç yaralanmalarının görülme sıklı̆̆ı her klinik ortamda farklılık göstermekte olup, akut bakım ortamlarında görülme oranının \%10-29 aralığında değiştiği bildirilmiştir (Türsen, 2013; Coyer ve diğerleri 2015; Katran, 2015; Karadağ ve Gümüşkaya, 2006). Klinikler ile kıyaslandığında Yoğun Bakım Ünitelerinde YBÜ'lerinde basınç yaralanması oluşum riskinin 3.8 kat daha fazla olduğu ve \%33-56 oranlarında değiştiği belirlenmiştir (Türsen, 2013; Katran, 2015; Coyer ve diğerleri 2016). Bu yüksek oranlar, basınç yaralanmalarını önlemenin hasta güvenliği için gerekli ve önemli olduğunu göstermektedir. Bu yaralanmaların önlenmesinde, riskli hastaların belirlenmesi, risk faktörlerini ve etkilerini ortadan kaldırmaya yönelik girişimlerin planlanması ve 
uygulanması önemlidir (Posthauer ve diğerleri 2015). Riskli hastaların belirlenmesinede ve risk faktörlerine dayalı önleme girişimlerinin planlanmasında hemşirelerin rolü önemlidir. Hastanın birincil bakımından sorumlu olan hemşireler, geçerli ve güvenilir risk değerlendirme araçları ile basınç yarası riskini değerlendirmeli ve kanıt temelli öneriler doğrultusunda bu riskleri ortadan kaldırmaya yönelik girişimleri planlamalıdır (Tanrıkulu ve Dikmen 2017; Katran 2015).

\section{Basınç Yaralanması Risk Faktörleri}

Basınç yaralanmalarının oluşumunda en etkili faktör basınçtır (Ersoy ve diğerleri 2013). Basınç dişında doku toleransını etkileyen sürtünme, yırtılma ve nem gibi dışsal faktörler ile ileri yaş, yetersiz beslenme, hareketsizlik, Diyabetes Mellitus (DM) gibi kronik hastalıklar, sepsis, oksijen yetersizliği, duyu ve motor kayıplar gibi içsel faktörler de basınç yaralanmalarının oluşumunda etkili olmaktadır (Desneves, Todorovic, Cassar ve Crowe, 2005; NPUAP, EPUAP ve PPPIA 2014; Berlowitz, Berman ve Schmader, 2018). Basınca eşlik eden nem ve sürtünme kuvveti, derinin epidermis ve dermis tabakasının soyulmasına neden olmakta, dokular arasında oluşan yırtılma kuvveti ise kan damarlarının sıkışmasına neden olarak dokunun beslenmesini bozmaktadır (Karadağ ve Gümüşkaya, 2006; Katran, 2015). Doku üzerine uygulanan herhangi bir basıncın, basınç yaralanmasına yol açıp açmaması basıncın yoğunluğu, süresi ve dokunun toleransı ile yakından ilişkilidir (Igarashi, Yamamoto, Gushiken, Tanaka ve Okamoto, 2013; Altunel ve Kartal, 2019). Igarashi ve diğerleri (2013), immobilize hastaların kemik çıkıntıları üzerindeki yumuşak dokunun $60-70 \mathrm{mmHg}$ 'lik basıncı 3 veya 5 dakika tolere edebileceğini, aynı basınca 1-2 saat süre ile maruz kalınması durumunda ise basınç yaralanması ile sonuçlanan iskemik değişikliklerin oluştuğunu belirlemiştir.

Yetersiz ve dengesiz beslenmenin neden olduğu hipoalbüminemi kaynaklı ödem de doku beslenmesini bozarak ve dokunun basınca ve sürtünmeye toleransını azaltarak basınç yaralanmalarının oluşumunu kolaylaştırmaktadır (Doley, 2010; Cereda, Neyens, Caccıalanza, Rondanelli ve Schols, 2017). Serum albümin düzeyi $3.5 \mathrm{mg} / \mathrm{dl}$ (Doley 2010) veya $3.3 \mathrm{mg} / \mathrm{dl}$ altına düştügünde (Serra ve ark. 2014) basınç yaralanması oranının arttığı belirlenmiştir. Benzer bir çalışmada ise, albumin $\leq 2,5 \mathrm{~g} / \mathrm{dL}$ olmasının basınç yaralanması riskini artırdığ 1 saptanmıştır (Ersoy ve diğerleri 2013). Ulusal Basınç Yaralanması Danışma Paneli'nin 2019 yılı rehberinde de, yetersiz ve dengesiz beslenmenin basınç yaralanması riskini artıran önemli bir faktör olduğu (Kanıt Düzeyi $(\mathrm{KD})=\mathrm{C})$ vurgulanmıştır (NPUAP, EPUAP ve PPPIA 2019). Türsen (2013), geniş basınç yaralanmalı ( $\geq 100$ $\mathrm{cm}^{2}$ ) hastalarda, çinko, demir, fosfat ve C vitamini eksikliği olduğunu bildirmiştir. Bu nedenle, basınç yaralanması riski yüksek hastalarda hemşire mutlaka hastanın beslenmesini değerlendirilmeli ve eksikliklerin giderilmesi için beslenme uzmanı ve hekim ile işbirliği yaparak hastanın beslenmesini düzenlemelidir (Tanrıkulu ve Dikmen 2017; Katran 2015). Basınç yaralanması riskini değerlendirmek için kullanılan ölçeklerin bazılarında da hastanın beslenme durumu dikkate alınmaktadır (Katran, 2015; Fırat Kılıç ve Sucudağ, 2017; Altunel ve Kartal, 2019). Örneğin, Braden Risk Değerlendirme Ölçeği'nde hastanın beslenmesi çok kötü, olasılıkla yetersiz, yeterli, kusursuz olarak, Waterlow Ölçeği'nde ise orta, az, nazogastrik tüp ya da sadece sıvı, anoreksik ya da oral almıyor olarak değerlendirilmektedir (Fırat K1lıç ve Sucudağ, 2017).

Yeterli ve dengeli beslenme sadece basınç yaralanmalarının önlenmesinde değil, tedavisinde de etkilidir (NPUAP, EPUAP ve PPPIA 2014; Doley, 2010; vanAnholt ve diğerleri 2010; Shahin ve diğerleri 2010).

\section{Basınç Yaralanmalarının Tedavisinde Beslenmenin Önemi}

Basınç yaralanmalarının tedavisinde, protein, karbonhidrat, vitamin ve mineral gibi temel besin öğelerinin yeterli miktarda alınması önemlidir (Landau, 2014; Cereda ve diğerleri 2017; Berlowitz ve diğerleri 2018). Yeterli ve dengeli beslenmenin, özellikle protein, vitamin ve mineral takviyelerinin ve yeterli sıvı alımının yara iyileşmesini hızlandırdığı bilinmektedir (Cereda ve diğerleri 2017; Thomas, 2014; NPUAP, EPUAP ve PPPIA 2014; Serra ve diğerleri 2014; vanAnholt ve diğerleri 2010; Desneves ve diğerleri 2005). Bu nedenle, basınç yaralanmalı hastaların multidisipliner bakımında mutlaka beslenme desteği yer almalıdır (Landau, 2014; Shahin ve diğerleri 2010; Posthauer ve diğerleri 2015; Cereda ve diğerleri 2017). 
Ulusal Basınç Yaralanması Danışma Paneli'nin 2019 yılı rehberinde, basınç yaralanması riski olan hastalara mutlaka beslenme taramasının yapılması $(\mathrm{KD}=\mathrm{B})$, yüksek riskli hastalara bireyselleştirilmiş beslenme planı uygulanması $(\mathrm{KD}=\mathrm{B})$ ve günde en az 1.2-1.5 gram $/ \mathrm{kg}$ protein ve $30-35 \mathrm{kcal} / \mathrm{kg}$ kalori almalarının sağlanması $(\mathrm{KD}=\mathrm{B})$, yeterli beslenmenin sağlanamadığı hastalara normal diyete ek olarak yüksek kalorili ve proteinli takviyeler verilmesi $(\mathrm{KD}=\mathrm{C})$ önerilmektedir (NPUAP, EPUAP ve PPPIA 2014, 2019). Ek olarak bu rehberde, yeterli beslenemeyen Evre II basınç yaralanmalı hastalara yüksek kalorili ve proteinli, arginin, çinko ve oral antioksidan içeren oral besin takviyeleri verilmesi veya enteral beslenme sağlanması da $(\mathrm{KD}=\mathrm{B})$ önerilmektedir (NPUAP, EPUAP ve PPPIA 2019).

Basınç yaralanmalı hastaların protein, enerji, vitamin ve mineral alımını artırmak için oral ve enteral sıvı beslenme takviyeleri kullanılmakta (Schneider ve Yahia, 2019; Cereda ve diğerleri 2015; Sakae, Agata, Kamide ve Yanagisawa, 2013; Bauer, Isenring ve Waterhouse, 2013; van Anholt ve diğerleri 2010; Schols, Heyman ve Meijer, 2009; Heyman, Van De Looverbosch, MAijer ve Schols, 2008), bu takviyelere en az sekiz hafta devam edilmesinin yara iyileşmesini hızlandırdığı belirtilmektedir (Cereda ve diğerleri 2017; Ohura ve diğerleri 2011). Yapılan çalışmalar, arginin, A, C, E vitamini ve çinko ile zenginleştirilmiş yüksek proteinli oral beslenme takviyeleri ile bakır $(\mathrm{Cu})$, demir $(\mathrm{Fe})$ ve folik asit takviyelerinin, kollajen sentezini ve epitelizasyonu artırarak basınç yaralanmalarının iyileşmesini hızlandırdığını ortaya koymuştur (Heyman ve diğerleri 2008; Cereda, Gini, Pedrolli ve Vanotti, 2009, Cereda ve diğerleri 2015, Cereda ve diğerleri 2017; Schols ve diğerleri 2009; van Anholt ve diğerleri 2010; Sakae ve diğerleri 2013; Thomas, 2014; Posthauer ve diğerleri 2015; Schneider ve Yahia, 2019).

Spesifik aminoasitlerden olan arginin, kollajen sentezine ve hücresel yenilenmeye katkı sağlayan önemli bir amino asittir (Cereda ve diğerleri 2017). Arginin insülin salgılanmasını uyarır ve aminoasitlerin hücrelere taşınmasını destekleyerek hücrelerde protein sentezini sağlar (Posthauer ve diğerleri 2015). Arginin takviyesinin basınç yaralanmalarındaki etkinliğinin incelendiği bir sistematik derlemede; arginin ile desteklenmiş oral beslenme takviyelerinin ortalama üç hafta uygulanmasının yara boyutunu azalttığı ve yara iyileşmesini hızlandırdığı belirtilmiştir (Schneider ve Yahia. 2019). Dört Avrupa ülkesinde yürütülen bir çalışmada, normal diyet ve yara bakımına ek olarak, sekiz hafta süresince günde üç kez spesifik arginin ve $C$ vitamini içeren yüksek kalorili $200 \mathrm{ml}$ oral besin takviyesi verilen Evre III ve/veya Evre IV basınç yaralanmalı hastaların yara iyileşmesinin hızlandığı belirlenmiştir (van Anholt ve diğerleri 2010). Benzer şekilde sekiz hafta süresince 1.24 $\mathrm{g} / \mathrm{kg} /$ gün protein verilenler ile kıyaslandığında $1.62 \mathrm{~g} / \mathrm{kg} /$ gün protein verilen basınç yaralanmalı hastaların yara boyutunun anlamlı oranda daha fazla küçüldüğü saptanmıştır (Ohura ve diğerleri 2011). Bu sonuçlardan farklı olarak Bauer ve diğerleri (2013), sekiz hafta süresince günde iki porsiyon $10.5 \mathrm{~g}$ protein, 251 kalori ve günde iki kez $4.5 \mathrm{~g}$ arginin verilen basınç yaralanmalı hastalar ile kıyaslandığında, günde iki porsiyon 9 g protein ve 251 kalori verilen hastaların yara iyileşmesinin daha hızlı olduğunu belirlemiş ve klinik ortamda standart beslenme takviyesinin yeterli olabileceğini vurgulamıştır.

Basınç yaralanmalı hastaların beslenmesine eklenmesi gereken önemli minerallerden biri çinkodur (Sakae ve diğerleri 2013; Thomas, 2014; Palmieri ve diğerleri 2019). Yara iyileşmesi için gerekli olan kollajenin sentezinde önemli bir kofaktör olan çinko, protein, DNA ve RNA sentezi ve epitelizasyon için de gerekli bir mineraldir (Posthauer ve diğerleri 2015). Sakae ve diğerleri (2013), oral çinko desteğinin basınç yaralanmalarının iyileşmesinde olumlu etkisinin olduğunu belirlemiş̧ir. Benzer şekilde Cereda ve diğerleri (2015) yaptıkları randomize kontrollü çalışmada, sekiz hafta süresince arginin, çinko ve antioksidanlarla birleştirilmiş beslenme desteği uygulanan basınç yaralanmalı hastalarda yara iyileşmesinin hızlandığını saptamıştır.

Basınç yaralanmalı hastaların beslenmesine eklenmesi önerilen başlıca vitaminler A, E ve C vitaminleridir. A vitaminin steroidlerin hücre çoğalmasını engelleyici ve doku yenilenmesini bozucu etkilerini azalttı̆̆ını ve yara iyileşmesini artırdığı (Thomas, 2014; Doley, 2010), C vitaminin de fibroblast çoğalmasını uyararak kollajen sentezini artırdığı ve yara iyileşmesini hızlandırdığı bilinmektedir (Posthauer ve diğerleri 2015; Cereda ve diğerleri 2017). Ancak, C vitamini eksikliği olmayan hastalara verilen C vitamininin yara iyileşmesini hızlandırdığına dair yeterli kanıt bulunmamaktadır (Thomas, 2014; Doley, 2010). Bir antioksidan olan E 
vitaminin yara iyileşmesindeki rolü kesin olarak bilinmemekle birlikte, epitelizasyonu hızlandırdığı ve skar oluşumunu azalttığı belirtilmektedir (Doley, 2010). E vitamininin yara iyileşmesindeki etkisini güncel araştırmalar 1şı̆̆ında inceleyen bir derlemede, mevcut araştırmaların yetersiz olduğu ve daha fazla araştırma yapılması gerekliliği vurgulanmıştır (Hobson, 2016).

\section{SONUÇ ve ÖNERILER}

$\mathrm{Bu}$ derleme, basınç yaralanmalarının önlenmesinde ve tedavisinde, yeterli ve dengeli beslenmenin ve besin takviyelerinin önemine dikkati çekmektedir. Mevcut çalışmaların ve rehberlerin çoğunluğunda, basınç yaralanmalı hastalara verilen arginin, çinko ve $\mathrm{C}$ vitamini ile zenginleştirilmiş besin takviyelerin yara iyileşmesini hızlandırdığı, bazılarında ise bu etkinin kesin olmadığı, yeni çalışmalara gereksinim olduğu vurgulanmaktadır. Basınç yaralanmalı hastalara bakım veren hemşireler, hastanın beslenmesini değerlendirmeli, yeterli ve dengeli beslenmeyi sağlamaya yönelik bireyelleştirilmiş bakım girişimlerini uygulamalı ve yapacakları kanıt düzeyi yüksek araştırmalar ile bu hastalara özgü beslenme protokollerinin oluşturulmasına rehberlik etmelidir.

\section{Finansal Destek}

Çalışmada herhangi bir finansal destek kullanılmamıştır.

\section{Çıkar çatışması}

Yazarlar arasında herhangi bir çıkar çatışması yoktur.

\section{Yazarlık Katkıları}

Tasarım/Design: M.Y., S.Y.; Literatür Tarama/Literature Search: M.Y.; Yazma/Writing: M.Y., S.Y.; Çalışmanın Değerlendirilmesi ve Eleştirel İnceleme/ Study Evaluation and Critical Review: S.Y., M.Y.

\section{KAYNAKÇA}

Altunel, C.T., Kartal, S.P. (2019). Dekübit ve bası ülserleri. Türkiye Klinikleri, p.87-94. https://www.turkiyeklinikleri.com/article/en-dekubit-ve-basi-ulserleri-85382.html

Bauer, J.D, Isenring E, Waterhouse M. (2013).The effectiveness of a specialised oral nutrition supplement on outcomes in patients with chronic wounds: a pragmatic randomised study. J Hum Nutr Diet, 26(5), 452-8. https://doi.org/10.1111/jhn.12084.

Berlowitz, D., Berman, R. S., \& Schmader, K. E. (2018). Clinical staging and management of pressure-induced skin and soft tissue injury. Up To Date: https://www.uptodate.com/contents/clinical-staging-and-management-of-pressure-inducedskin-and-soft-tissue-injury. (Erişim:2020, 10 Temmuz).

Cereda, E., Gini, A., Pedrolli, C., Vanotti, A. (2009). Disease-specific, versus standard, nutritional support for the treatment of pressure ulcers in institutionalized older adults: a randomized controlled trial. J Am Geriatr Soc, 57(8), 1395-1402. https://doi.org/10.1111/j.1532-5415.2009.02351.x.

Cereda, E., Klersy, C., Serioli, M., Crespi, A., D’Andrea, F. (2015). Oligo Element Sore Trial Study Group. A nutritional formula enriched wit harginine, zinc, andantioxidant for the healing of pressure ulcers: a randomized trial. Ann Intern Med, 3;162(3),167-74. https://doi.org/10.7326/M14-0696

Cereda, E., Neyens, J.C.L., Caccialanza, R., Rondanelli, M., Schols, J.M.G.A.(2017). Efficacy of a disease-specific nutritional support for pressure ulcer healing: a systematic review and meta-analysis. J Nutr Health Aging, 21(6), 655661. https://doi.org/10.1007/s12603-016-0822-y

Chaboyer, W., Bucknall, T., Webster, J., McInnes, E., Banks, M., Wallis, M., Gillespie, B., Whitty, J.A., Thalib, L., Roberts, S., Cullum, N. (2015). Introducing a care bundle to prevent pressure injury (INTACT) in at-risk patients: A protocol for a cluster randomised trial. International Journal of Nursing Studies, (52),1659-1668. https://doi.org/10.1016/j.ijnurstu.2015.04.018

Coyer, F., Gardner, A., Doubrovsky, A. et al.(2015) Reducing pressure injuries in critically ill patients by using a patient skin integrity care bundle (InSPiRE). Am J Crit Care, 24(3),199-209. https://doi.org/10.4037/ajcc2015930

Coyer, F., Miles, S., Gosley, S., Fulbrook, P., Sketcher-Baker, K., Cook, J.L., Whitmore, J. (2016) Pressure injury prevalence in intensive care versus non-intensive care patients: a state-wide comparison. Australian Critical Care, 4:10367314. https://doi.org/10.1016/j.aucc.2016.12.003

Desneves, K.J., Todorovic, B.E., Cassar, A., Crowe, T.C. (2005) Treatment with supplement aryarginine, vitamin C and zinc in patients with pressure ulcers: a randomised controlled trial. Clin Nutr, 24, 979-987. https://doi.org/10.1016/j.clnu.2005.06.011 
Doley, J. (2010) Nutrition management of pressure ulcers. Nutrition in Clinical Practice. 25(1), 50-60. https://doi.org/10.1177/0884533609359294

Ersoy, E.O., Öcal, S., Öz, A., Yılmaz, P., Arsava, B., Topeli, A. (2013) Yoğun bakım hastalarında bası yarası gelişiminde rol oynayabilecek risk faktörlerinin değerlendirmesi. Yoğun Bakım Dergisi, 13, 4, 9-12. http://www.jcritintensivecare.org/uploads/pdf/pdf_DCY_56.pdf

EUAP-NPUAP-PPIA (European Pressure Ulcer Advisory Panel- National Pressure Ulcer Advisory Panel. 2019. Prevention and Treatment of Pressure ulcers/injuries: Quick reference guide. file://C:/Users/Toshiba/Downloads/ggg-quickreference-guide-version04dec2019-secured\%20(2).pdf .Erişim Tarihi: 10 Mayıs 2020.

European Pressure Ulcer Advisory Panel (EPUAP), National Pressure Ulcer Advisory Panel (NPUAP).Prevention and Treatment of Pressure Ulcers: Clinical Practice Guideline. Washington, DC: National Pressure Ulcer Advisory Panel; 2009.

Fırat Kılıç, H., Sucudağ, G. (2017) The Scales Frequently Used in the Assessment of Pressure Sores. G.O.P. Taksim E.A.H. JAREN, 3(1),49-54. https://www.journalagent.com/jaren/pdfs/JAREN_3_1_49_54.pdf

Heyman, H., Van De Looverbosch, D.E., Meijer, E.P., Schols, J.M. (2008) Benefits of an oral nutritional supplement on pressure ulcer healing in long-term care residents. J Wound Care, 17(11),476-484. https://doi.org/10.12968/jowc.2008.17.11.31475

Hobson, R. (2016) Vitamin E and wound healing: an evidence-based review.Int Wound J.,Jun;13(3):331-5.doi: 10.1111/iwj.12295. https://doi.org/10.1111/iwj.12295

Igarashi, A., Yamamoto-Mitani, N., Gushiken, Y., Tanaka, Y.T.M., Okamoto, Y. (2013) Prevalence and incidence of pressure ulcers in Japanese longterm-care hospitals. Archives of Gerontology and Geriatrics, 56(1), 220-6. https://doi.org/10.1016/j.archger.2012.08.011

Karadağ, M., Gümüşkaya, N. (2006) The incidence of pressure ulcers in surgical patients: a sample hospital in Turkey. Journal of Clinical Nursing, 15, 413-421. https://doi.org/10.1111/j.1365-2702.2006.01369.x

Katran, H.B. (2015) The research on the incidence of pressure sores in a surgical intensive care unit and the risk factors affecting the development of pressure sores. G.O.P. Taksim E.A.H. JAREN, 1(1), 8-14. https://jarengteah.org/eng/jvi.aspx?pdir=jaren\&plng=eng\&un=JAREN-10820

Landau, G.B. (2014) Nutrition and pressure ulcers. Wound Healing Southern Africa, 7(2). 40-44. https://journals.co.za/content/mp_whsa/7/2/EJC169897

NPUAP-EUAP-PPPIA (European Pressure Ulcer Advisory Panel- National Pressure Ulcer Advisory Panel-Pan Pacific Pressure Injury Alliance) 2014. Prevention and Treatment of Pressure ulcers: Quick reference guide. ISBN-13: 978-09579343-6-https://www.epuap.org/wp-content/uploads/2010/10/NPUAP-EPUAP-PPPIA-Quick-Reference-Guide-2014DIGITAL.pdf. Erişim Tarihi: 10 Mayıs 2020.

Ohura, T., Nakajo, T., Okada, S., Omura, K., Adachi, K. (2011) Evaluation of effects of nutrition intervention on healing of pressure ulcers and nutritional states (randomized controlled trial). Wound Repair Regen,19, 330-6. https://doi.org/10.1111/j.1524-475X.2011.00691.x

Palmieri, B., Vadala, M., Laurino, C. (2019) Nutrition in wound healing: investigation of the molecular mechanisms, a narrative review. Journal of Wound Care. 28(10), 683-693. https://doi.org/10.12968/jowc.2019.28.10.683

Posthauer, M.E., Banks. M., Dorner. B., Schols, J.M. (2015) The role of nutrition for pressure ulcer management: national pressure ulcer advisory panel, European pressure ulcer advisory panel, and pan pacific pressure injury alliance white paper. Adv Skin Wound Care. Apr;28(4), 175-88. doi: 10.1097/01.ASW.0000461911.31139.62

Sakae, K., Agata, T., Kamide, R., Yanagisawa, H. (2013) Effects of L-Carnosine and its Zinc complex (Polaprezinc) on pressure ulcer healing. Nutrition in Clinical Practice, 28(5), 609-616. https://doi.org/10.1177/0884533613493333

Schneider, K.L., Yahia, N. (2019) Effectiveness of Arginine Supplementation on Wound Healing in Older Adults in Acute and Chronic Settings: A Systematic Review. Advances in Skin \& WoundCare, 32, 457-62. doi: 10.1097/01.ASW.0000579700.20404.56

Schols, M.G.A., Heyman, H, Meijer, E.P. (2009) Nutritional support in the treatment and prevention of pressure ulcers: An overview of studies with an arginine enriched Oral Nutritional Supplement. Journal of Tissue Viability, 18, 72-79. https://doi.org/10.1016/j.jtv.2009.03.002

Serra, R., Caroleo, S., Buffone, G., Lugarà, M., Molinari, V., Tropea, F., Amantea, B., Franciscis, S. (2014) Low serum albümin level as an independent risk factor for the onset of pressure ulcers in intensive care unit patients. International Wound Journal. 11, 550-3. https://doi.org/10.1111/iwj.12004

Shahin, E.S.M., Meijers, J.M.M., Schols, J.M.G.A., Tannen, A., Halfen, R.J.G., Dassen, T. (2010) The relationship between malnutrition parameters and pressure ulcers in hospitals and nursing homes. Nutrition, 26, 886-889. https://doi.org/10.1016/j.nut.2010.01.016

Tanrıkulu, F, Dikmen, Y. (2017). Yoğun Bakım Hastalarında Basınç Yaraları: Risk faktörleri ve Önlemler. J Hum Rhythm. 3(4),177-182. https://dergipark.org.tr/tr/pub/johr/issue/33484/373544 
Thomas, D.R. (2014)Role of nutrition in the treatment and prevention of pressure ulcers. Nutrition in Clinical Practice 29(4), 466-472. https://doi.org/10.1177/0884533614539016

Türsen, Ü.(2013) Ülser Tedavisinde $\quad$ Yara Örtüleri. $\quad$ Turk $\quad$ J $\quad$ Dermatol, 7, 61-71. http://cms.galenos.com.tr/Uploads/Article 9747/61-71.pdf

vanAnholt, R.D., Sobotka, L., Meijer, E.P, et al. (2010) Specific nutritional support accelerates pressure ulcer healing and reduces wound care intensity in non-malnourished patients. Nutrition, 26(9),867-872. https://doi.org/10.1016/j.nut.2010.05.009 


\section{EXTENDED ABSTRACT}

Background: Pressure injuries, which are largely preventable complications, are serious chronic wounds that result in increasing morbidity and mortality rates, prolonged hospital stay, and imposing additional costs (NPUAP, EPUAP ve PPPIA 2014; Chaboyer ve ark. 2015). It has been determined that $10-30 \%$ of the patients who are hospitalized may suffer from pressure injuries. It is showed that some factors such as inactivity, hypoalbuminemia, inadequate and unbalanced nutrition can increase the risk of pressure injuries (Coyer ve ark. 2015; Coyer ve ark. 2016). In the National Pressure Injury Advisory Panel guideline in 2019, it was emphasized that in addition to factors such as pressure, tear, and humidity, inadequate and unbalanced nutrition are important factors that can increase the risk of pressure injuries (NPUAP, EPUAP ve PPPIA 2019). Türsen (2013) in a study confirmed the role of nutritional deficiency in increasing pressure injury in patients. Pressure, friction / tearing, irritation are considered as the main factors causing pressure injury development. There are many preparatory factors (old age, uncontrolled diabetes, sepsis, neurological and vascular disease, spinal cord injury, trauma) in the formation of pressure injury, and one of the most important points is malnutrition / deficiency (Desneves et al 2005). Nutritional deficiencies / disorders and pressure injuries lead to a decrease in the normal functions of the individual, a decrease in the quality of life, an increase in the morbidity and mortality rate, an increase in the length of hospital stay and therefore the cost increase. Therefore, early detection of nutritional problems is very important in all patients with pressure injuries. Research results have shown that nutritional deficiency plays a role in the development of pressure injuries and tissue healing (Inözü et al.2012; Cereda et al.2017).

Aim: This review aimed to discuss the effective nutritional supplements in the treatment of pressure injuries and their influencing role in wound healing based on current literature.

Result: A review of the literature showed that adequate intake of essential nutrients such as protein, carbohydrates, vitamins, and minerals is important in the treatment of pressure injuries (Landau 2014; Cereda ve ark. 2017; Berlowitz ve ark. 2018). In the National Pressure Injury Advisory Panel guideline in 2019, it is recommended to give high-calorie and protein supplements $(\mathrm{KD}=\mathrm{C})$ in addition to the normal diet to patients who cannot consume adequate nutrition (NPUAP, EPUAP ve PPPIA 2014, 2019). The importance of adequate protein intake in wound healing is known. It is thought that there is a nutritional - deficiency (zinc, iron, phosphate, vitamin C) especially in pressure injuries above $100 \mathrm{~cm} 2$. Especially, additional arginine supplementation has been found to contribute to pressure injury recovery. (Thomas 2014; Türsen 2013; İnözü et al.2012). Therefore, the amount of protein to be taken daily should be 1.25-1.5 grams for each kilogram of body weight. It is also important for the patient to take adequate fluids, vitamins and minerals (NPUAP, EPUAP and PPPIA 2014). Besides, studies have shown that consuming high protein oral nutritional supplements enriched with vitamins $\mathrm{A}, \mathrm{C}, \mathrm{E}$ and zinc and copper $(\mathrm{Cu})$, iron $(\mathrm{Fe})$, and folic acid supplements can accelerate the healing of pressure injuries by increasing collagen synthesis and epithelization (Heyman ve ark. 2008; Cereda ve ark. 2009,2015,2017; Schneider ve Yahia 2019). Especially vitamin C plays an important role in cellular immunity, fibroblast proliferation, and collagen synthesis Vitamin A deficiency has been associated with delayed wound healing and increased susceptibility to infection. Zinc; It is necessary for protein synthesis and various enzymes involved in the healing process as a result of injury. In addition, it plays an important role in wound healing due to its various effects on immune functions (Cereda et al 2017). Also, it has been determined that the administration of oral nutritional supplements supplemented with arginine, one of the specific amino acids, for an average of three weeks can reduce the wound size and accelerates wound healing (Schneider ve Yahia 2019). Moreover, a multi-center study confirmed that the wound healing of patients with Stage III and/or Stage IV pressure injuries who were given $200 \mathrm{ml}$ high calorie oral nutritional supplement containing specific arginine and vitamin C three times a day for eight weeks was accelerated (van Anholt ve ark 2010).

Conclusion: This review highlighted the importance of an adequate and balanced diet and nutritional supplements in the prevention and treatment of pressure injuries. Nurses who take care of patients with pressure injuries are recommended to assess the patient's nutrition status, implement individualized care interventions to ensure adequate and balanced nutrition, and create nutritional protocols specific to these patients with the guide of evidencebased outcomes of recent studies. 